\title{
Effect of heat treatment on the structure and magnetic properties of Sm-Fe alloys obtained by mechanical alloying
}

\author{
Nikolay Razumov ${ }^{1 *}$, and Aleksandr Verevkin ${ }^{1}$ \\ ${ }^{1}$ National Technology Initiative Center of Excellence in Advanced Manufacturing Technologies at \\ Peter the Great Saint-Petersburg Polytechnic University, 195251, 29, Polytechnicheskaya st., Saint- \\ Petersburg, Russian Federation
}

\begin{abstract}
The effect of heat treatment on the structure and magnetic properties of $\mathrm{Sm}-\mathrm{Fe}$ alloys obtained by mechanical alloying was investigated. The crystallization temperature of $\mathrm{Sm}_{2} \mathrm{Fe}_{17}$, an amorphous alloy obtained by mechanical alloying, was determined using differential scanning calorimetry. Based on these results, various samples were annealed at different isothermal holding temperatures, and those with the best magnetic properties were found. Experimental studies show that decreasing the isothermal holding temperature from $750{ }^{\circ} \mathrm{C}$ to $630{ }^{\circ} \mathrm{C}$ increases magnetic characteristics nearly four times. The saturation magnetization, romance and coercivity of the $\mathrm{Sm}_{2} \mathrm{Fe}_{17}$ powder were $121 \mathrm{emu} / \mathrm{g}, 28.5 \mathrm{emu} / \mathrm{g}$ and $800 \mathrm{Oe}$, respectively.
\end{abstract}

\section{Introduction}

The development of civilization and technological progress necessitate the production of devices of a higher level and a new purpose. Along with new design and design solutions in many cases, such devices require the use of special or new materials. New materials may be subject to special requirements for functional, technological or economic reasons. Magnetic materials are of particular interest.

Magnetic materials are used by mankind for several millennia. However, the great significance of magnetic materials for technological progress humanity felt only in the middle of the XIX century after Faraday discovered the law of electromagnetic induction. Then it became possible to design and manufacture power generators, motors, transformers and other apparatuses and devices for electrical engineering and communications equipment. The development of electronics means of generation and transmission of data is not possible without the development of magnetic materials.

Many researchers have become interested in the nitrides and carbides of the intermetallic compound $\mathrm{Sm}_{2} \mathrm{Fe}_{17}$ by reasone of their excellent magnetic properties, discovered by Coey and Sun in 1990 [1]. This intermetallic material is a promising replacement for permanent magnets that is different from widely-used $\mathrm{Nd}$-based magnets. It has uniaxial anisotropy with a high anisotropic field and a Curie temperature exceeding $450{ }^{\circ} \mathrm{C}$.

\footnotetext{
*Corresponding author: n.razumov@onti.spbstu.ru
} 
Several techniques have been developed for syntheszing $\mathrm{Sm}_{2} \mathrm{Fe}_{17}$-type magnetic materials, including casting [2], melt spinning, hydrogen disproportionation desorption recombination [3], reduction-diffusion [4], and mechanical alloying (MA) [5]. In all cases, MA proved to be an efficient technique for the low cost, large scale production of powders $[2,6]$. Mechanical alloying has been recognized as a technique for synthesizing ultrafine powder materials through solid-state diffusion under intense mechanical deformations $[7,8]$, and MA elevates coercivity [9].

Numerous published reports have established that the master alloy, $\mathrm{Sm}_{2} \mathrm{Fe}_{17}$, produced via MA, consists of two main parts: nanosized crystalline $\alpha-\mathrm{Fe}$ and an amorphous Sm-Fe phase $[10,11]$. Heat treatment of the as-milled powder in a vacuum is required to obtain fully crystalline $\mathrm{Sm}_{2} \mathrm{Fe}_{17}$. The grain size can be modified by heat treating. Generally, the $\mathrm{Sm}-\mathrm{Fe}$ alloy is isothermallly held between $700{ }^{\circ} \mathrm{C}$ and $850{ }^{\circ} \mathrm{C}$; greater temperatures have been used $[5,8,12,13]$. A single-phase $\mathrm{Sm}_{2} \mathrm{Fe}_{17}$ intermetallic compound with a rhombohedral $\mathrm{Th}_{2} \mathrm{Zn}_{17}$ crystal structure forms during heat treatment. A strong relationship between particle and grain size and magnetic properties exists.

In this paper, we describe studies of the effect of heat treatment on the structure and magnetic properties of non-nitrogenated Sm-Fe alloys obtained by MA. The crystallization temperature of partially amorphous Sm-Fe alloys was determined using differential scanning calorimetry (DSC). The results led us to anneal various samples at different isothermal holding temperatures and compare their magnetic properties. Grain size, lattice parameters, and magnetic properties were functions of the isothermal holding temperature.

\section{Experimental}

\section{Materials}

High purity Fe (d90<300 $\mu \mathrm{m}, 99.96 \%$ purity; NevaReaktiv, LLC, Russia) and Sm (d90 $<700 \mu \mathrm{m}, 99.9 \%$ purity; Huizhou Gl Technology Co., LTD, PRC) were used as initial components.

\section{Preparation of Sm-Fe powders}

Sm-Fe-based alloys were prepared by MA of initial powders using a Pulverisette-4 varioplanetary mill (Fritsch GmbH, Germany). This technique applies a short isothermal holding time. The obtained nanocrystalline powders are very reactive and are easily subjected to nitriding. Moreover, nanocrystalline materials have an adapted microstructure for extrinsic magnetic properties [14].

To prevent oxidation of the initially-formed powder, all operations were handled inside a glove box under a high-purity nitrogen atmosphere. Powders initially nominally composed of Fe and 15 at.\% Sm (5 at.\% excess Sm) were milled for $10 \mathrm{~h}$ using a planetary ball mill with hard metal vials and balls under an argon atmosphere and a ball-to-powder mass ratio of 10:1 using a disc rotation velocity of $200 \mathrm{rpm}$. The main-to-planetary disc rotation velocity ratio was 1:-1.5. The as-milled powders were annealed in a vacuum furnace (VBF-1200X; MTI Corporation, USA) under a medium vacuum of about $150 \mathrm{mtorr}$ at $630{ }^{\circ} \mathrm{C}$ to $750{ }^{\circ} \mathrm{C}$ for 30 minutes. The excess 5 at. \% Sm was used to compensate for possible Sm evaporation during the isothermal hold. 


\section{Characterizations}

The powder morphology and distribution of elements per volume of powder particle were examined using a scanning electron microscope (Mira 3 Tescan; Tescan Orsay Holding a.s, Czech Republic) at $20 \mathrm{kV}$ equipped with an Oxford INCA Wave 500 add-on device.

Thermal analysis was performed using a DSC device for thermal testing of materials (Setaram SETSYS Evolution 16; Setaram Instrumentation SAS, France) under an argon flow of $30 \mathrm{ml} \mathrm{min}-1$, a heating rate of $5^{\circ} \mathrm{C}$ min-1, and a temperature range of $20^{\circ} \mathrm{C}$ to $1000{ }^{\circ} \mathrm{C}$.

The crystal structures of the obtained powders were characterized by X-ray diffraction (XRD) on a Brucker D2 Phaser (Bruker Corporation, USA) in Co-K $\alpha$-radiation $(\lambda=1.79026$ $\AA)$ at a scanning step of $0.05^{\circ}(2 \theta$ scale $)$ for $0.5 \mathrm{~s}$ in the range of $2 \theta=30^{\circ}$ to $100^{\circ}$. TOPAS software was used to carry out the Rietveld refinement of the XRD patterns and to analyze the crystal structures and calculate the lattice parameters and grain size. The quality of the Rietveld refinement was evaluated in terms of goodness of fit (GOF) and the R factor $\left(\mathrm{R}_{\mathrm{wp}}\right)$. Generally, when GOF is close to 1 and $R_{w p}$ is less than $10 \%$, the result can be considered reliable.

Magnetic properties were measured at ambient temperature $(300 \mathrm{~K})$ using a vibrating sample magnetometer (Lakeshore 7410 model VSM; Lake Shore Cryotronics, Inc, USA) at the maximum magnetic field of $22 \mathrm{kOe}$, a measurement sensitivity of $4 \mathrm{emu}$, and a measurement step of 200 Oe.

\section{Results and discussion}

\section{Powder Morphology}

The SEM micrographs in Fig. 1a and $1 \mathrm{~b}$ show the morphologies of as-milled $\mathrm{Sm}_{2} \mathrm{Fe}_{17}$ powders. The as-milled powder appeared in the form of irregular highly agglomerated particles with an average size of $8 \mu \mathrm{m}$. The elemental analysis obtained by energy-dispersive $\mathrm{X}$-ray spectroscopy indicated uniform and homogeneous distribution of each initial element in the particle. The XRD results showed that a two-phase mixture of amorphous Sm-Fe and $\alpha$-Fe was formed in the powder. The broadening peaks corresponded to $\alpha$-Fe (110) and (200) planes and showed grain refinement and an accumulation of defects and strains induced by MA.

(a)

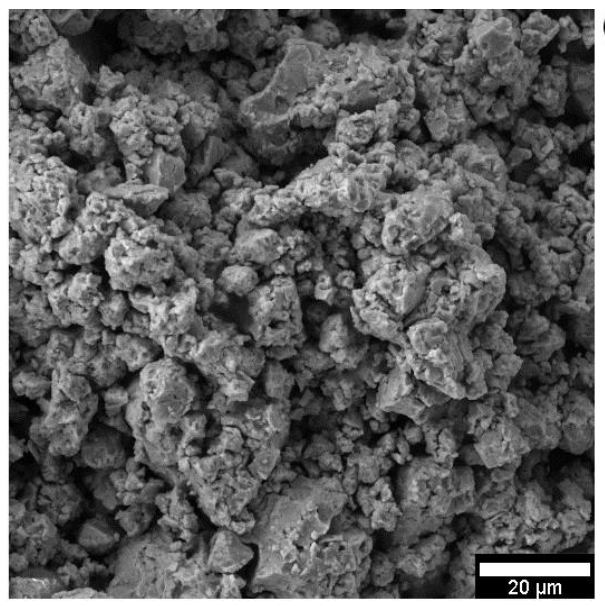

(b)

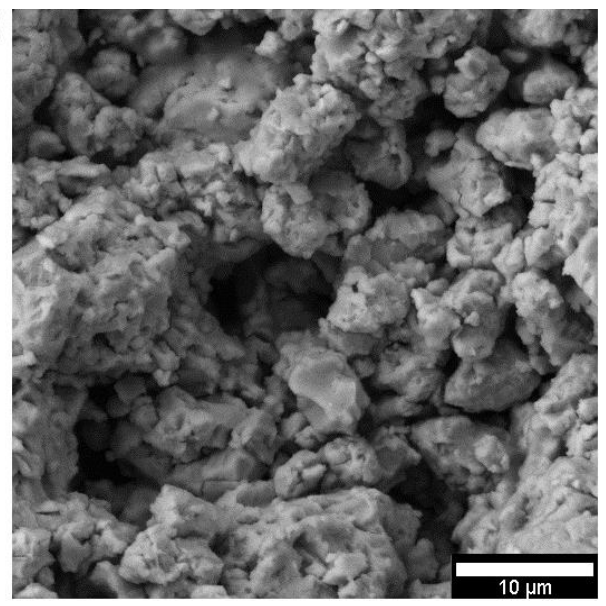

Fig.. 1. SEM micrographs of as-milled powder. 
The crystallization temperature of the amorphous $\mathrm{Sm}_{2} \mathrm{Fe}_{17}$ alloy was determined using DSC, yielding three characteristic peaks as shown in Fig. 2. The first peak corresponded to the formation $\mathrm{SmFe}_{3}$ phases. Tan [13] showed that the free energy barrier for the nucleation of $\mathrm{SmFe}_{3}$ is smaller than that of $\mathrm{Sm}_{2} \mathrm{Fe}_{17}$, thus the reaction $\mathrm{Sm}+3 \mathrm{Fe} \rightarrow \mathrm{SmFe}_{3}$ proceeds at lower temperatures. Small thermal fluctuations at $510{ }^{\circ} \mathrm{C}$ to $570{ }^{\circ} \mathrm{C}$ cannot agitate nucleations in $\mathrm{Sm}_{2} \mathrm{Fe}_{17}$ at appreciable rates. The second peak corresponded to the formation $\mathrm{Sm}_{2} \mathrm{Fe}_{17}$ phases. This stable chemical compound was found to form at $626^{\circ} \mathrm{C}$ to $719^{\circ} \mathrm{C}$, and this was confirmed by XRD. The third peak was not determined, but the XRD phase compositions did not change with increasing heat treatment temperature. Therefore, this peak likely corresponds to the formation $\mathrm{SmFe}_{2}$ phases, though this was not indicated by XRD analysis. As shown in [13], the free energy barrier for nucleation of $\mathrm{SmFe}_{3}, \Delta \mathrm{G}\left(\mathrm{SmFe}_{3}\right)$, is lower than those for $\mathrm{SmFe}_{2}$ or $\mathrm{Sm}_{2} \mathrm{Fe}_{17} . \Delta \mathrm{G}\left(\mathrm{SmFe}_{3}\right)$ being less than $\Delta \mathrm{G}\left(\mathrm{Sm}_{2} \mathrm{Fe}_{17}\right)$ can be associated with the elimination of a larger number of $\mathrm{Sm} / \mathrm{Fe}$ interfaces during nucleation of $\mathrm{SmFe}_{3}$, and $\Delta \mathrm{G}\left(\mathrm{SmFe}_{3}\right)$ being less than $\Delta \mathrm{G}\left(\mathrm{SmFe}_{2}\right)$ can be associated with lower driving forces for the reaction leading to the formation of $\mathrm{SmFe}_{2}$. Based on these results, a series of experiments was designed to determine the effect of heat treatment on the magnetic properties of $\mathrm{Sm}_{2} \mathrm{Fe}_{17}$ alloy.

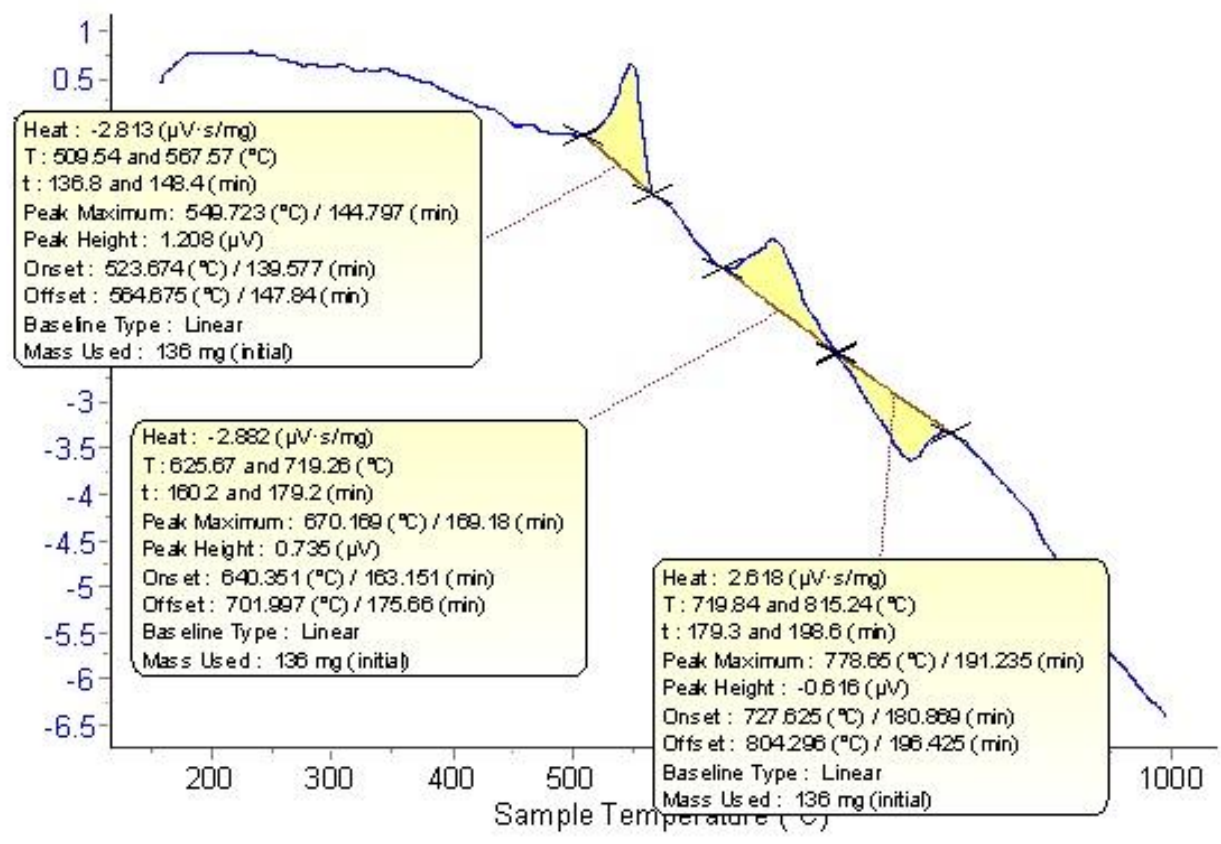

Fig. 2. Differential scanning calorimetry curve of the $\mathrm{Sm}_{2} \mathrm{Fe}_{17}$ alloy obtained by mechanical alloying.

\section{XRD Measurements}

Fig. 3 shows the XRD patterns after isothermal holds at $630{ }^{\circ} \mathrm{C}, 660^{\circ} \mathrm{C}, 690{ }^{\circ} \mathrm{C}$, and 750 ${ }^{\circ} \mathrm{C}$. All XRD patterns for these annealed powders were successfully indexed based on $\mathrm{Sm}_{2} \mathrm{Fe}_{17}, \mathrm{SmFe}_{3}$, and $\mathrm{Sm}_{2} \mathrm{O}_{3}$. The $\mathrm{Sm}_{2} \mathrm{Fe}_{17}$ rhombohedral $\mathrm{Th}_{2} \mathrm{Zn}_{17}$-type phase was shown by the main diffraction peaks (00-051-0910 pattern) at $34.92^{\circ}, 42.44^{\circ}, 49.42^{\circ}, 49.85^{\circ}, 51.09^{\circ}$, and $56.13^{\circ}$, corresponding to the (113), (300), (220), (303), (006), and (223) crystal planes. The peaks on all three XRD patterns at $40.35^{\circ}, 41.85^{\circ}, 47.22^{\circ}, 48.03^{\circ}$, and $64.17^{\circ}$ corresponded to the (110), (113), (021), (202), and (211) crystal planes of $\mathrm{SmFe}_{3}(00-050$ 1450 pattern). The diffraction peaks at $33.45^{\circ}, 35.95^{\circ}, 38.85^{\circ}$, and $55.15^{\circ}$ corresponded to 
the (222), (321), (400), and (440) crystal planes of $\mathrm{Sm}_{2} \mathrm{O}_{3}\left(00-015-0813\right.$ pattern). The $\mathrm{SmFe}_{3}$ was formed because the $\mathrm{Sm}$ content in the initial powder mixture was higher than that required for formation of a nominal $\mathrm{Sm}_{2} \mathrm{Fe}_{17}$ phase. This excess was included to account for possible losses of Sm during heat treatment or additions of $\alpha$-Fe from wear debris from the vials and balls during MA. Peaks for the free $\alpha$-Fe phase were not detected. Decreasing the isothermal holding temperature from $750{ }^{\circ} \mathrm{C}$ to $630^{\circ} \mathrm{C}$ led to a simultaneous broadening and shifting of the $\mathrm{Sm}_{2} \mathrm{Fe}_{17}$ diffraction peaks.

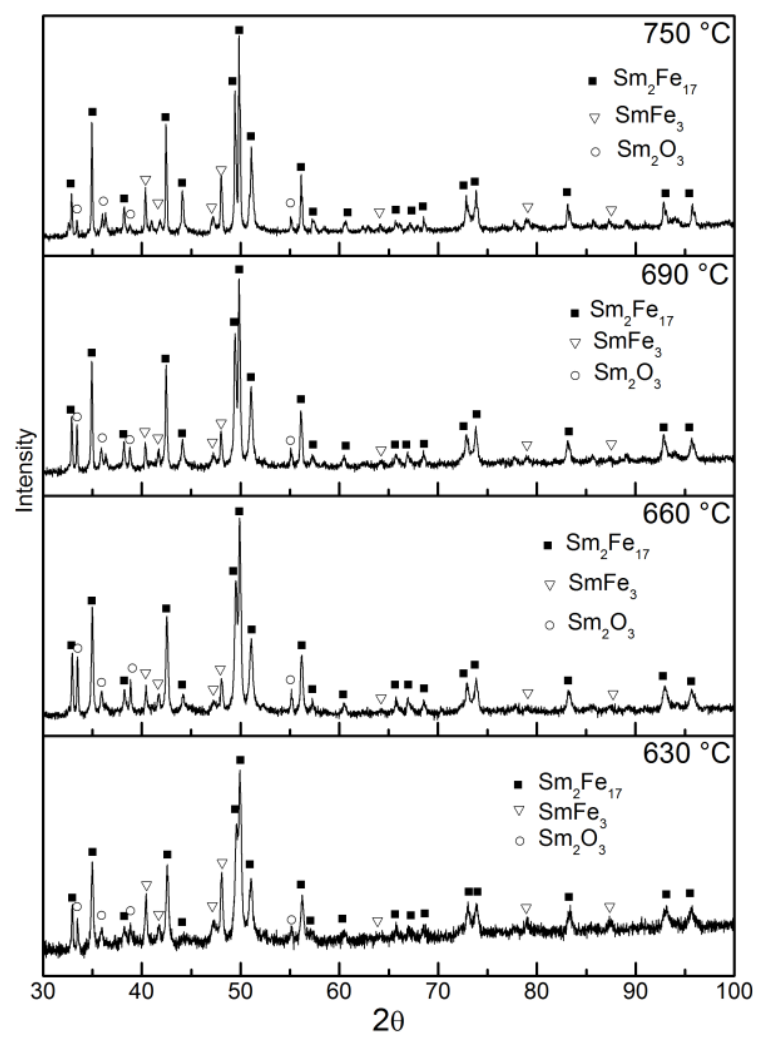

Fig.. 3. X-ray diffraction patterns of $\mathrm{Sm}_{2} \mathrm{Fe}_{17}$ alloy after isothermal hold at various temperatures.

The best Rietveld refinement $\left(\mathrm{GOF}=1.23 ; \mathrm{R}_{\mathrm{wp}}=3.34 \%\right)$ was for powder annealed at 630 ${ }^{\circ} \mathrm{C}$, resulting in three crystalline phases. One was $\mathrm{Sm}_{2} \mathrm{Fe}_{17}$ with lattice parameters $\mathrm{a}=$ 8.5425(7) $\AA, \mathrm{c}=12.4692(15) \AA$, and $\mathrm{V}=788.03(15) \AA^{3}$. Another was $\mathrm{SmFe}_{3}$ with lattice parameters $\mathrm{a}=5.1837(5) \AA, \mathrm{c}=24.856(7) \AA$, and $\mathrm{V}=578.4(2) \AA^{3}$. The third was $\mathrm{Sm}_{2} \mathrm{O}_{3}$ with lattice parameters $\mathrm{a}=10.9350(15) \AA$ and $\mathrm{V}=1307.6(5) \AA^{3}$. Increasing the isothermal holding temperature to $750{ }^{\circ} \mathrm{C}$ changed the lattice parameters from $\mathrm{a}=8.5425(2)$ to $\mathrm{a}=$ $8.55253(14) \AA$ and from $\mathrm{c}=12.4692(2)$ to $\mathrm{c}=12.4374(3) \AA$. The largest lattice volume was achieved at $660{ }^{\circ} \mathrm{C}$ and was $788.46(8) \AA^{3}$. The relative changes in the lattice parameters a, c, and $\mathrm{V}$ can be seen in Fig. 4. The corresponding Rietveld refinement GOF and $\mathrm{R}_{\mathrm{wp}}$ values were 1.47 and $2.55 \%$ when the hold temperature was $660{ }^{\circ} \mathrm{C}, 1.44$ and $2.61 \%$ when it was $690{ }^{\circ} \mathrm{C}$, and 1.41 and $2.57 \%$ when it was $750{ }^{\circ} \mathrm{C}$. The Rietveld refinement results of the $\mathrm{Sm}_{2} \mathrm{Fe}_{17}$ alloy XRD patterns are shown in Table 1. 


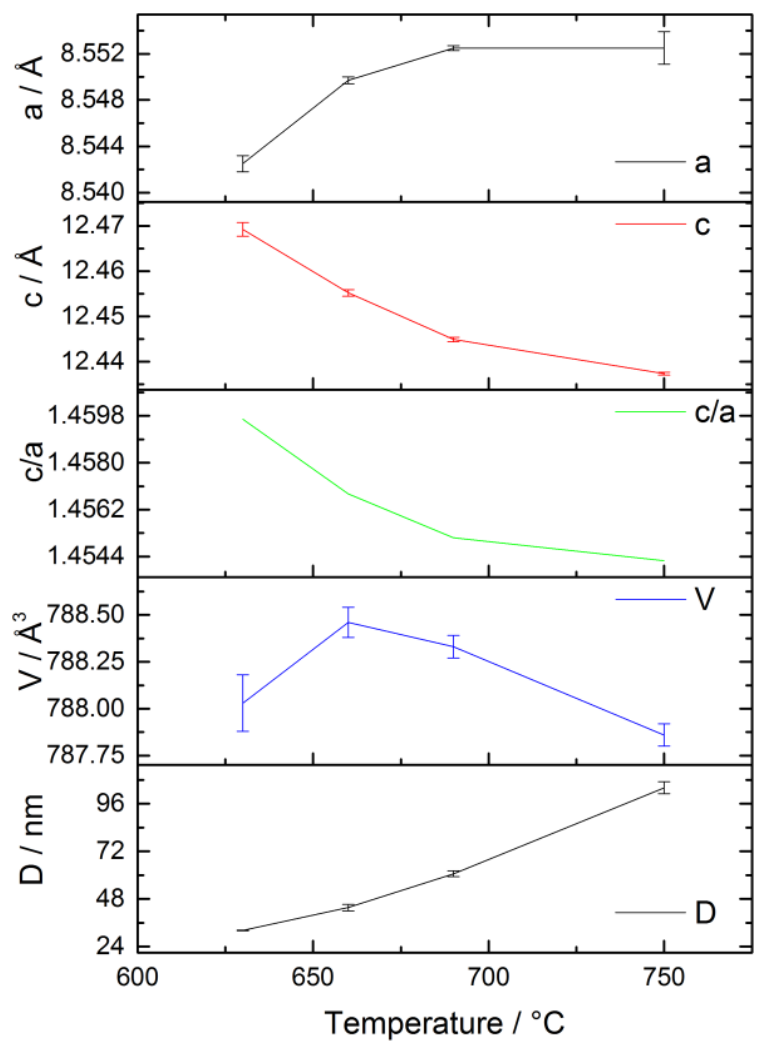

Fig. 4. Lattice parameters a and c, c/a ratio, unit-cell volume (V), and grain size (D) of $\mathrm{Sm}_{2} \mathrm{Fe}_{17}$ alloy as a function of heat treatment temperature.

Table 1. Crystallographic parameters from the Rietveld refinement of $\mathrm{Sm}_{2} \mathrm{Fe}_{17}$ alloys annealed at various temperatures.

\begin{tabular}{ccccc}
\hline Heat & \multicolumn{3}{c}{ Lattice parameters } & $\mathrm{D}(\mathrm{nm})$ \\
\cline { 2 - 4 } $\begin{array}{c}\text { treatment } \\
\text { temperatur }\end{array}$ & $\mathrm{a}(\AA)$ & $\mathrm{c}(\AA)$ & $\mathrm{V}\left(\AA^{3}\right)$ & \\
$\mathrm{e},{ }^{\circ} \mathrm{C}$ & & & & \\
\hline $630^{\circ} \mathrm{C}$ & $8.5425(7)$ & $12.4692(15)$ & $788.03(15)$ & $32.2(2)$ \\
$660^{\circ} \mathrm{C}$ & $8.5497(3)$ & $12.4552(7)$ & $788.46(8)$ & $43.7(16)$ \\
$690^{\circ} \mathrm{C}$ & $8.5525(2)$ & $12.4449(5)$ & $788.33(6)$ & $60.7(15)$ \\
$750{ }^{\circ} \mathrm{C}$ & $8.5525(14)$ & $12.4374(3)$ & $787.86(1)$ & $104(3)$ \\
\hline
\end{tabular}

Notes: $\mathrm{V}=$ unit cell volume; $\mathrm{D}=$ grain size.

The c parameter of the $\mathrm{Th}_{2} \mathrm{Zn}_{17}$-unit cell decreased, and the a parameter increased, with greater isothermal holding temperatures (Fig. 4). The c/a ratio showed that the c parameter grew at a higher rate than the $a$ parameter decreased. This preferential distortion of the $\mathrm{Th}_{2} \mathrm{Zn}_{17}$-unit cell along the a- and c-axes may be indicative of remaining defects and strains after low-temperature isothermal holding. The diffraction peaks of the $\mathrm{Sm}_{2} \mathrm{Fe}_{17}, \mathrm{SmFe}_{3}$, and $\mathrm{Sm}_{2} \mathrm{O}_{3}$ phases narrowed with rising isothermal holding temperature, indicating better crystallinity at higher temperatures. The volume of the $\mathrm{Th}_{2} \mathrm{Zn}_{17}$ phase was extracted by Rietveld refinement of the XRD data. The overall volume of the unit cell increased with increasing temperature, up to $660{ }^{\circ} \mathrm{C}$. Thereafter, it decreased with temperature (Fig. 4). 
The XRD data also showed that, as a result of isothermal holding at $630{ }^{\circ} \mathrm{C}$, a nanocrystalline structure was formed with a grain size of 32(2) $\mathrm{nm}$. Crystal size increased with isothermal holding temperature to 100 to $110 \mathrm{~nm}$.

\section{Magnetic Measurements}

Hysteresis loops for non-magnetized samples are presented in Fig. 5. It can be seen that the coercive force of the samples increased from 200 to 800 Oe through increases in isothermal holding temperature (Fig. 5a). Coercivity increased with grains size reduction (Table 1). Yosida [15] and Khazzan et al. [16] showed that the coercive field value and the magnetization reversal process depend not only on chemical composition, temperature, and magnetic anisotropy, but also strongly on microstructure. Higher coercivities can be achieved when grains are finer $[15,18]$. When isothermal holding temperature is low, the sample often has many defects resulting from high-energy milling; in this case, crystallite sizes are very small. It is well known that crystalline size increases with isothermal holding temperature. Therefore, grain size is optimal after an isothermal hold at $630{ }^{\circ} \mathrm{C}$. The c parameter and grain size were found to be strongly correlated to magnetic properties.
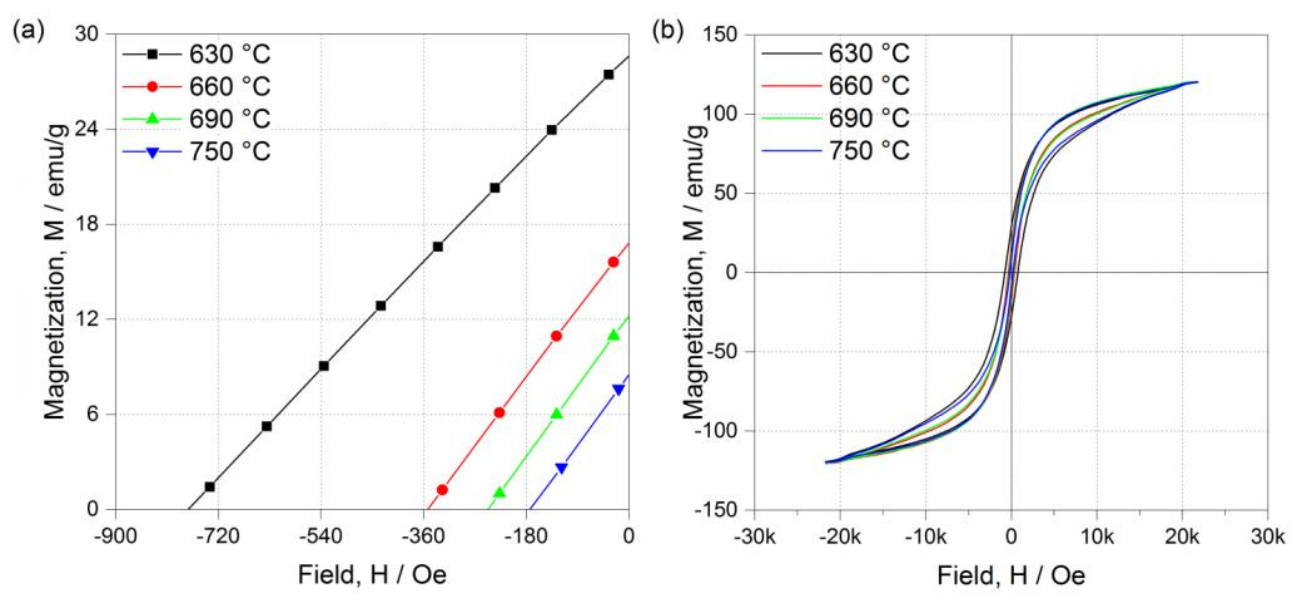

Fig. 5. Hysteresis loops of $\mathrm{Sm}_{2} \mathrm{Fe}_{17}$ alloys formed using isothermal holds at various temperatures.

As depicted in Table 2, most $\mathrm{Sm}_{2} \mathrm{Fe}_{17}$ powders, produced using different processes that resulted in much larger grain or particle sizes, $(0.3$ to $20 \mu \mathrm{m})$, showed much lower coercivities, ranging between 240 and 480 Oe. This is the result of the size effect of the $\mathrm{Sm}_{2} \mathrm{Fe}_{17}$ powder. Only Yun et al. [19] used a modified reduction-diffusion process to synthesize $\mathrm{Sm}_{2} \mathrm{Fe}_{17}$ nanopowders, achieving coercivities greater than 1000 Oe.

Table 2. Magnetic properties of $\mathrm{Sm}_{2} \mathrm{Fe}_{17}$ alloy synthesized by various processes.

\begin{tabular}{ccccc}
\hline Process & $\begin{array}{c}\text { Particle size, } \\
\mathrm{D}(\mu \mathrm{m})\end{array}$ & $\begin{array}{c}\text { Coercivity, } \\
\mathrm{H}_{\mathrm{c}}(\mathrm{Oe})\end{array}$ & $\begin{array}{c}\text { Saturation } \\
\text { Magnetization, } \\
\mathrm{M}_{\mathrm{s}}(\mathrm{emu} / \mathrm{g})\end{array}$ & Ref. \\
\hline MA & 8 & 800 & 121 & This study \\
MRD process & $0.1-0.3$ & 1000 & 128 & {$[\mathbf{1 9 ]}$} \\
Arc melting & $<50$ & 300 & 110 & {$[\mathbf{2 3}]$} \\
Induction melting & $<25$ & 550 & 117 & {$[\mathbf{2 4}]$} \\
R-D process & $5-10$ & 300 & $110-130$ & {$[4]$} \\
HDDR & $<3$ & 600 & 130 & {$[3]$} \\
\hline
\end{tabular}




\section{Conclusion}

Formation temperature range of the stable chemical compound $\mathrm{Sm}_{2} \mathrm{Fe}_{17}$ was determined using DSC. Best magnetic properties archived $630{ }^{\circ} \mathrm{C}$. This temperature corresponds to the beginning of the $\mathrm{Sm}_{2} \mathrm{Fe}_{17}$ formation. $\mathrm{In}_{2} \mathrm{Sm}_{2} \mathrm{Fe}_{17}$, the single domain is approximately $350 \mathrm{~nm}$ [20]. Below this grain size, coercivity should rapidly reduce with grain size; we observed abnormal coercivity in ultrafine crystallite powders. The field of $22 \mathrm{kOe}$ which may be generated by VSM magnetometer are below magnetization field required for saturation of approx. $40 \mathrm{kOe}$ [21] of $\mathrm{Sm}_{2} \mathrm{Fe}_{17}$ intermetallic compound. Proper magnetization might result in better magnetic values [22].

\section{References}

1. J. M. D. Coey, H. J. Sun Magn. Magn. Mater., 87(3) (1990)

2. N. Imaoka, T. Iriyama, S. J. Itoh Alloy Comp., 222(1) (1995)

3. J. Sun, C. Cui, Y. Zhang, L. Li, J. Gao, et al. Mater. Chem. Phys., 97 (2006)

4. J.-G. Lee, S.-K. Kang, P.-Z. Si, C.-J. J. Choi Magn., 16(2) (2011)

5. A. A. Popovich, A. S. Verevkin, N. G. Razumov, T. A. Popovich, ARPN J. Eng. Ap. Sc., 11(3) (2016)

6. Q. Fang, X. An, F. Wang, Y. Li, et al. J. Magn. Magn. Mater., 410 (2016)

7. C. H. Lee, T. Fukunaga, Y. Yamada, U. Mizutani, H. J. Okamoto, Phase Equilibria., 14 (1993)

8. C.-H.Lee, Y.-S. Kwon Met.Mater. Int., 8(2) (2002)

9. X. Lv, W. Liu, W. Cui, X. Zhao, W. Ren, Z. Zhang, J.Appl.Phys., 103 (2008)

10. L. Schultz, K. Schnitzke, J. Wecker, M. Katter, C. Kuhrt, J. Appl. Phys., 70(10) (1991)

11. K. Majima, N. Niimi, S. Katsuyama, H. Nagai, H. Tomizawa, J. Alloy Comp., 193(1) (1993)

12. C. Kuhrt, K. Schnitzke, L. Schultz J.Appl.Phys., 73(10) (1993)

13. M. J. Tan, Mater. Sci., 29(5) (1994)

14. I. Nehdi, L. Bessais, C. Djega-Mariadassou, M. Abdellaoui, H. Zarrouk, J. Alloy Comp., 351 (2003)

15. Y.Yoshida, The International Forum on Magnetic Applications, Technologies and Materials (Magnetics 2016), Jacksonville, Fl, USA, 21-22 January (2016)

16. S. Khazzan, L. Bessais, G. Van Tendeloo, N. J. Mliki, Magn. Magn. Mater., 363 (2014)

17. K. Uestuener, M.Katter, Rodewald W, IEEE Trans. Magn., 42(10) (2006)

18. C. H. Chen, S. Kodat, M. H. Walmer, S. F. Cheng, M. A. Willard, V. G. Harris J. Appl. Phys., 93(10) (2003)

19. J.-C. Yun, S.-M. Yoon, J.-Y. Lee, J.-P. Choi, J.-S. Lee, Mater. Trans., 55 (10) (2014)

20. K. Kobayashi, X.-L. Rao, J. M. D. Coey, D. Givord, J. Appl. Phys., 80 (1996)

21. O. Isnard, S. Miraglia, M. Guillot, D.J. Fruchart, Appl. Phys. 75(10) (1994)

22. M. Przybylski, D. Kapelski, B. Ślusarek, S. Wiak. Sensors 16(4) (2016)

23. L. Zhao, L. Zheng, Funct. Mat. Let. 6(4) (2013)

24. T. Saito, H. Miyoshi, D.J. Nishio-Hamane, Alloy Comp. 519 (2012) 